\section{Isolation of Mononuclear Cells from Tonsillar Tissue}

\author{
Andrew Johnston, ${ }^{1}$ Sigrun L. Sigurdardottir, ${ }^{2}$ and Judith J. Ryon ${ }^{3}$ \\ ${ }^{1}$ Department of Dermatology, University of Michigan, Ann Arbor, Michigan \\ ${ }^{2}$ Department of Immunology, Landspitali-University Hospital, Reykjavik, Iceland \\ ${ }^{3}$ National Institute of Allergy and Infectious Diseases, Bethesda, Maryland
}

\begin{abstract}
Located on the inside of the throat, the paired palatine tonsils form part of the first major barrier protecting the digestive and respiratory tracts from potentially invading microorganisms. The tonsils have a surface of stratified squamous epithelium that extends into deep and branched crypts lined by reticulated epithelium, which in parts may only be one cell thick. Organized in the sub-epithelial space are B cell rich lymphoid follicles. $\mathrm{T}$ cells are mostly located in the extra-follicular spaces with a very high CD4:CD8 T cell ratio. In addition to the $\mathrm{T}$ and $\mathrm{B}$ cell subsets, six phenotypes of dendritic cells (DC) have been identified in the tonsils: Langerhans cells in the squamous epithelium, germinal center DC, and follicular DC in the germinal center, and another three DC phenotypes that are located in the extra-follicular area (interdigitating DC, plasmacytoid DC, and lympho-epithelial symbiosis-DC). Here, we describe the isolation of tonsil mononuclear cells from fresh human tonsil. Curr. Protoc. Immunol. 86:7.8.1-7.8.4. (C) 2009 by John Wiley \& Sons, Inc.
\end{abstract}

Keywords: tonsils $\bullet \mathrm{T}$ cells $\bullet \mathrm{B}$ cells $\bullet$ lymphocytes

This unit describes a protocol for the isolation of lymphoid cell populations from tonsillar tissue. The procedure can also be applied with little or no modification to spleen and lymph node tissue.

Human tonsils are the most readily available lymphoid organs and are often used as a source of large numbers of cells characteristic of local lymphoid tissue. Mononuclear cells are isolated by mechanical disruption of tonsil tissue followed by Ficoll density gradient centrifugation. Cells may then be separated into subpopulations according to general protocols used for peripheral blood lymphocytes (UNITS 7.1-7.7).

CAUTION: When working with human blood, cells, or infectious agents, biosafety practices must be followed (see Chapter 7 introduction).

NOTE: All solutions and equipment coming into contact with cells must be sterile, and proper sterile technique must be used accordingly.

\section{Materials}

Fresh human palatine tonsils

Isotonic saline or Hanks balanced salt solution (HBSS) with antibiotics (see recipe), $4^{\circ} \mathrm{C}$

Complete RPMI medium supplemented with $10 \%$ (v/v) human AB serum (APPENDIX 2A) with $5 \mu \mathrm{g} / \mathrm{ml}$ gentamicin and $0.5 \mu \mathrm{g} / \mathrm{ml}$ amphotericin B

Forceps, sterile

$150 \times 25-\mathrm{mm}$ petri dishes

UNIT 7.8

BASIC

PROTOCOL

Immunologic

Studies in

Human

7.8.1

Published online August 2009 in Wiley Interscience (www.interscience.wiley.com).

DOI: $10.1002 / 0471142735 . i m 0708$ s86

Copyright $(2009$ John Wiley \& Sons, Inc. 
Disposable sterile scalpels (Swann-Morton, cat. no. 0511 or equivalent)

Straight iris scissors (Fisher, cat. no. S17338 or equivalent)

Dissecting forceps (VWR, cat. no. 382027-384 or equivalent)

3 -in. stainless steel sieve with $250-\mu \mathrm{m}$ mesh (Thomas Scientific, cat. no. 8323-N48

or equivalent)

5 -ml plastic syringe plunger

50-ml polycarbonate centrifuge tubes

3-ml transfer pipet (single-use Pasteur pipets; Sarstedt, cat. no. 861171)

40- $\mu \mathrm{m}$ plastic cell strainer (Fisher, cat. no. 22363547)

Low-speed centrifuge with fixed-angle or swinging-bucket rotor (e.g., Sorvall

RT-6000B with $\mathrm{H}-1000 \mathrm{~B}$ rotor)

Additional reagents and equipment for Ficoll-Hypaque cell separation (UNIT 7.1) and cryopreservation of cells (APPENDIX $3 G$ )

1. Obtain fresh tonsils extracted from individuals undergoing routine tonsillectomy. Keep tissue in cold isotonic saline in a plastic container on ice until processing.

Since tissue viability decreases with time, process the tissue within 1 to $3 \mathrm{hr}$.

2. Using sterile forceps, place specimen on a large plastic petri dish and keep moistened with $2 \mathrm{ml} \mathrm{HBSS}$ with antibiotics.

3. Cut tissue into 3- to 10-mm fragments with scissors or scalpels.

4. Using sterile forceps, place tissue pieces into a stainless steel sieve that has been set inside a large plastic petri dish containing $2 \mathrm{ml}$ HBSS.

5. Push the lymphoid cells present in the tissue through the sieve using the flat end of a 5-ml plastic syringe plunger. Rinse remaining tissue two to three times with HBSS until clear.

6. Transfer equal volumes of cell suspension from the petri dish to 50-ml centrifuge tubes using a disposable sterile transfer pipet.

7. Add more cold HBSS and process remaining tissue fragments by repeating steps 4 to 6 twice more to free as many lymphocytes as possible from stroma. Discard any material remaining in the sieve.

8. After transferring all cells to centrifuge tubes, break up any cell clumps, suspend the cells by repeated pipetting, and pass through a sterile cell strainer. The final volume of cell suspension should be $35 \mathrm{ml} /$ tube.

Six to twelve tubes are usually required.

9. Overlay the cell suspension on $10 \mathrm{ml}$ Ficoll-Hypaque (UNIT 7.1). Centrifuge $20 \mathrm{~min}$ in a Sorvall H-1000B rotor at $1800 \mathrm{rpm}(1000 \times g)$, room temperature. Accelerate and decelerate without braking.

10. Collect mononuclear cells from interface and discard cell pellet containing fibroblasts and other cell debris (see UNIT 7.1).

11. Wash cells three times, each time with HBSS and resuspend in complete RPMI-10 medium for immediate use, or cryopreserve and store in liquid nitrogen freezer for future use.

Isolation of

Mononuclear

Cells from

Tonsillar Tissue

7.8.2

Supplement 86

Current Protocols in Immunology 


\section{REAGENTS AND SOLUTIONS}

Use deionized, distilled water in all recipes and protocol steps. For common stock solutions, see APPENDIX 2A; for suppliers, see APPENDIX 5.

\section{Hanks balanced salt solution with antibiotics}

HBSS (APPENDIX 2A) containing:

$100 \mathrm{U} / \mathrm{ml}$ penicillin

$100 \mu \mathrm{g} / \mathrm{ml}$ streptomycin

$5 \mu \mathrm{g} / \mathrm{ml}$ gentamicin

$0.5 \mu \mathrm{g} / \mathrm{ml}$ amphotericin B

\section{COMMENTARY}

\section{Background Information}

Investigators in the early 1970s first separated tonsillar lymphocytes from stroma by gentle teasing with small-gauge needles, and showed that these cells could be stimulated in vitro to produce immunoglobulin if the ratios of $\mathrm{T}$ and $\mathrm{B}$ cells were adjusted appropriately (Hoffmann et al., 1973; Sloyer et al., 1973). Preparation of single-cell suspensions was facilitated by the passage of cells through a fine-mesh sieve (Watanabe et al., 1974). Today, tonsils are most often used as a source of large numbers of human B cells, which are often further separated by size using countercurrent centrifugation (Muraguchi et al., 1983), or into fractions of differing density on Percoll gradients (Nakagawa et al., 1988). These techniques are described in relation to monocyte/ macrophage isolation in UNIT 7.6. Because of the large number of lymphocytes that can be extracted from a pair of tonsils, they are also a useful source of dendritic cells (Summers et al., 2001) despite comprising only $1 \%$ of the tonsil lymphoid population. In addition, they are also useful as a source of tissue NK cells, which, along with dendritic cells, participate in tonsillar innate immune responses (Strowig et al., 2008)

\section{Critical Parameters}

Storage in ice-cold isotonic saline solution or HBSS and rapid processing of cells as soon as possible after surgical removal are critical to maintaining viability. Routine use of antibiotics-including amphotericin B-is necessary to prevent contamination, although overgrowth can occur despite these precautions.

\section{Anticipated Results}

Tonsil specimens typically weigh from 2 to $10 \mathrm{~g}$. In general, larger tonsils from younger patients will contain large germinal centers and yield the greatest number of viable mononuclear cells. Total mononuclear cell yields will range from $5 \times 10^{8}$ to $5 \times$ $10^{9}$ cells per pair of tonsils. B cells comprise $60 \%$ to $70 \%$ of the cell population after Ficoll-Hypaque centrifugation, while $30 \%$ to $40 \%$ are $\mathrm{T}$ cells and $1 \%$ to $8 \%$ are monocytes (Watanabe et al., 1974). Dendritic cells comprise $<1 \%$ of the cell population (Hart and McKenzie, 1988).

\section{Time Considerations}

The total time required for this procedure depends on tonsil size. Average processing time is $\sim 2 \mathrm{hr}$. After separation on Ficoll, mononuclear cells may be cryopreserved (APPENDIX $3 G$ ). Further separation into subsets can be performed after thawing.

\section{Literature Cited}

Hart, D. and McKenzie, J. 1988. Isolation and characterization of human tonsil dendritic cells. J. Exp. Med. 168:157-170.

Hoffmann, M., Schmidt, D., and Oettgen, H. 1973. Production of antibody to sheep red blood cells by human tonsil cells in vitro. Nature 243:408410.

Muraguchi, A., Butler, J., Kehrl, J., and Fauci, A.S. 1983. Differential sensitivity of human B cell subsets to activation signals delivered by anti- $\mu$ antibody and proliferative signals delivered by a monoclonal B cell growth factor. J. Exp. Med. 157:530-546.

Nakagawa, T., Nakagawa, N., Ambrus, J.L., and Fauci, A.S. 1988. Differential effects of Interleukin 2 vs. B cell growth factor on human B cells. J. Immunol. 140:465-469.

Sloyer, J., Veltri, R., and Sprinkle, P. 1973. In vitro IgM antibody synthesis by human tonsil-derived lymphocytes. J. Immunol. 111:183-188.

Summers, K.L., Hock, B.D., McKenzie, J.L. and Hart, D.N. 2001. Phenotypic characterization of five dendritic cell subsets in human tonsils. Am. J. Pathol. 159:285-295.

Strowig, T., Brilot, F., Array, F., Bougras, G., Thomas, D., Muller, W.A., and Munz, C. 2008. Tonsillar NK cells restrict B cell transformation by the Epstein-Barr virus via IFN-gamma. PloS Pathog. 4:e27.
Immunologic Studies in Human 
Watanabe, T., Yoshizaki, K., Yagura, T., and Yamamura, Y. 1974. In vitro antibody formation by human tonsil lymphocytes. J. Immunol. 113:608-616.

\section{Key Reference}

Watanabe et al., 1974. See above.

Describes protocol and expected yields, as well as the determination of optimal conditions for in vitro synthesis of immunoglobulin by tonsil lymphocytes.

Isolation of Mononuclear Cells from Tonsillar Tissue

\subsection{4}

